\title{
Successful Balloon Mitral Valvuloplasty in 21-week Pregnant Patient with Severe Mitral Stenosis: A Case Report and Literature Review
}

\author{
Cynthia Yosephine Silitonga*, Nahar Taufiq, Budi Yuli Setianto \\ Department of Cardiology and Vascular Medicine, Faculty of Medicine, Public Health and Nursing, Universitas \\ Gadjah Mada - Dr. Sardjito General Hospital, Yogyakarta, Indonesia \\ *Corresponding author: \\ Cynthia Yosephine Silitonga, MD, - email: cynthiaysilitonga@yahoo.co.id \\ Department of Cardiology and Vascular Medicine, Faculty of Medicine, Public Health and Nursing, \\ Universitas Gadjah Mada - Dr. Sardjito Hospital \\ Jalan Farmako Sekip Utara, Yogyakarta, Indonesia 55281 \\ Manuscript submitted: October 16, 2018; Revised and accepted: March 1, 2019
}

\section{ABSTRACT}

Mitral stenosis is the most common manifestation of rheumatic heart disease. Hemodynamic changes during pregnancy increase the burden of the heart in pregnant women with cardiac abnormalities. A 33 years old woman, G3P1A1 is 21 weeks pregnant came to our hospital with a shortness of breath during daily activity, which was worsened since 3 months of pregnancy. The patient has been diagnosed with severe mitral stenosis. The results of echocardiography examination was left atrial dilatation, normal global function and left ventricular with ejection fraction $51 \%$, severe mitral stenosis Wilkin Score 8 with Mitral Valve area $0.53 \mathrm{~cm}^{2}$ and Mitral Valve Gradient $33 \mathrm{mmHg}$. Subsequently, Balloon Mitral Valvuloplasty was successfully performed. During and after the procedure there was no complication. The fetus was considered in stable condition.

Keywords: severe mitral stenosis; balloon mitral valvuloplasty; pregnant

\section{INTISARI}

Mitral stenosis merupakan manifestasi paling umum dari penyakit jantung rematik. Perubahan hemodinamik selama kehamilan semakin menambah beban jantung pada pasien hamil dengan kelainan jantung. Seorang Wanita, usia 33 tahun, G3P1A1, hamil 21 minggu datang ke Rumah Sakit Dr. Sardjito dengan keluhan sesak nafas saat aktifitas sehari-hari.Pasien telah didiagnosis dengan mitral stenosis. Hasil ekokardiografi menunjukkan dilatasi atrium kiri, fungsi global dan segmental ventrikel kiri baik dengan ejeksi fraksi $51 \%$, mitral stenosis severe Wilkin Score 8 dengan Mitral Valve Area $0,53 \mathrm{~cm}^{2}$ dan Mitral Valve Gradient $33 \mathrm{mmHg}$. Pasien dilakukan Balloon Mitral Valvuloplasty (BMV) di RSUP Dr. Sardjito dan berhasil baik. Selama dan sesudah tindakan tidak didapatkan komplikasi. Keadaan janin pasca tindakan dinilai baik. 


\section{INTRODUCTION}

Mitral stenosis (MS) is the most common manifestation of rheumatic heart disease. ${ }^{1}$ Hemodynamic changes during pregnancy increase the burden of the heart in pregnant women with cardiac abnormalities. Although the prevalence of cardiovascular complications in pregnancy is low, reaching one to three percent, but it is responsible for $10-15 \%$ for maternal mortality. ${ }^{2}$

In 20 countries worldwide where rheumatic heart disease remains endemic, the agestandardized prevalence is estimated at $>1 \%$ and greatest in women of childbearing age. ${ }^{3}$ In India the rheumatic heart disease contributes to approximately $69 \%$ of cardiac disorders seen in pregnancy. ${ }^{3}$ The maternal mortality rate in women with cardiac disease is as high as 7\%, and morbidity rate higher than $30 \%$ during pregnancy. ${ }^{4}$ Mitral stenosis (MS) due to rheumatic heart disease is the most common cause of maternal death from cardiac cause wordwide. The rate of maternal complications is proportional to severity of MS and ranges from $26 \%$ with mild MS to 67 $\%$ with severe MS. ${ }^{1}$ The fetal morbidity rate in developed countries also rises with severity of MS from $14 \%$ in pregnant patients with mild MS, $28 \%$ in MS moderate and 33\% in severe MS. Moderate and severe MS is rarely tolerable during pregnancy. ${ }^{2}$

Although MS is
asymptomatic, the cardiac
decompensation symptoms may
worsen with increasing gestational
age and delivery, provides both
maternal and fetal morbidity and
mortality. Interventions are

sometimes obligatory. Percutaneous intervention in pregnant women has been a concern for medical practitioners and patients related to radiation exposure. However, balloon mitral valvulopasty (BMV) is more recommended than surgery in severe MS pregnant patients with decompensated symptoms that are not resolved with medical therapy. We report a BMV procedure in 21 weeks pregnant women with severe mitral stenosis.

\section{CASE PRESENTATION}

A 33 years old woman, G3P1A1 is 21 weeks pregnant came to Dr. Sardjito Hospital with a shortness of breath during daily activity, which was worsened since 3 months of pregnancy. The complaintwas accompanied by swelling on both legs. She felt more comfortable to sleep with half-sitting position. Chest pain was denied. Patients did not complain of diarrhea, pain during urination, fever, dizziness nor palpitation. History of high blood pressure and high cholesterol is also denied, no previous history of heart attacks, diabetes mellitus, smoking, nor heart attacks in family member.

The complaints began since 7 years ago when she was pregnant for the first time. She began to feel shortness of breath and fainted couple times. She then had a miscarriage at 12 weeks gestation and had done curettage. She was told she had vascular heart disease and took medication and control with routine therapy of digoxin, furosemide and potassium supplementation. Three years later she had second pregnancy, with a history of spontaneous labor through vacuum extraction at 38 weeks gestation. The baby was born crying 
instantly, with body weight 2900 grams.

On physical examination we found that she was compos mentis. The blood pressure was $110 / 70$ $\mathrm{mmHg}$, pulse rate was 98 times per minute regularly, respiration rate was 24 times per minute, temperature was $36.2^{\circ} \mathrm{C}$, peripheral saturation was $95 \%$. Conjunctiva was not anemic, sclera not jaundice. There was elevated jugular venous pressure of $5+3 \mathrm{~cm} \quad \mathrm{H}_{2} \mathrm{O}$. Examination of the lung showed vesicular voices no rhonchi in both lungs. Cardiac examination was minimal cardiomegaly with widening the right heart margin, palpable ictus cordis between the ribs in the left midclavicula linea and right heart border at the lateral finger of the paralternal dextra line. Normal S1 and normal S2 sound, middiastolic murmur $2 / 4$ on apex. Abdominal examination showed uterine fundus was at height of five fingers below the navel, normal peristaltic. Liver and spleen were not palpable. Examination of the etremities showed warm extremities with no oedema. ECG examination was sinus rhythm, 72 times per minute, Right axis deviation (RAD), Left Atrial dilatation, and Right ventricular strain.

Laboratory examination was $\mathrm{Hb} 12.8 \mathrm{mg} / \mathrm{dL}, 37 \%$ hematocryte $37 \%$, leukocyte $12.33 \mathrm{~mm}^{3}$, platelets $267 \mathrm{~mm}^{3}$, creatinine $0.57 \mathrm{mg} / \mathrm{dL}$ and blood urea nitrogen (BUN) 7.7 $\mathrm{mg} / \mathrm{dL}$, SGOT $18 \mathrm{U} / \mathrm{L}$, SGPT $17 \mathrm{U} / \mathrm{L}$, blood sugar $92 \mathrm{mg} / \mathrm{dl}$, sodium 134 $\mathrm{mmol} / \mathrm{L}$, potassium $3.71 \mathrm{mmol} / \mathrm{L}$, chloride $98 \mathrm{mmol} / \mathrm{L}$.

The result of echocardiography examination was left atrial dilatation, normal global function and left ventricular with ejection fraction (EF) 51\%, no regional wall motion abnormality, normal left ventricular diastolic function, normal right ventricular systolic function, severe MS Wilkin Score 8 with Mitral valve area (MVA) $0.53 \mathrm{~cm}^{2}$ and mitral valve gradient (MVG) $33 \mathrm{mmHg}$. Medium-severe regurgitation tricuspid (TR) with moderate pulmonary hypertension (Figure 2).

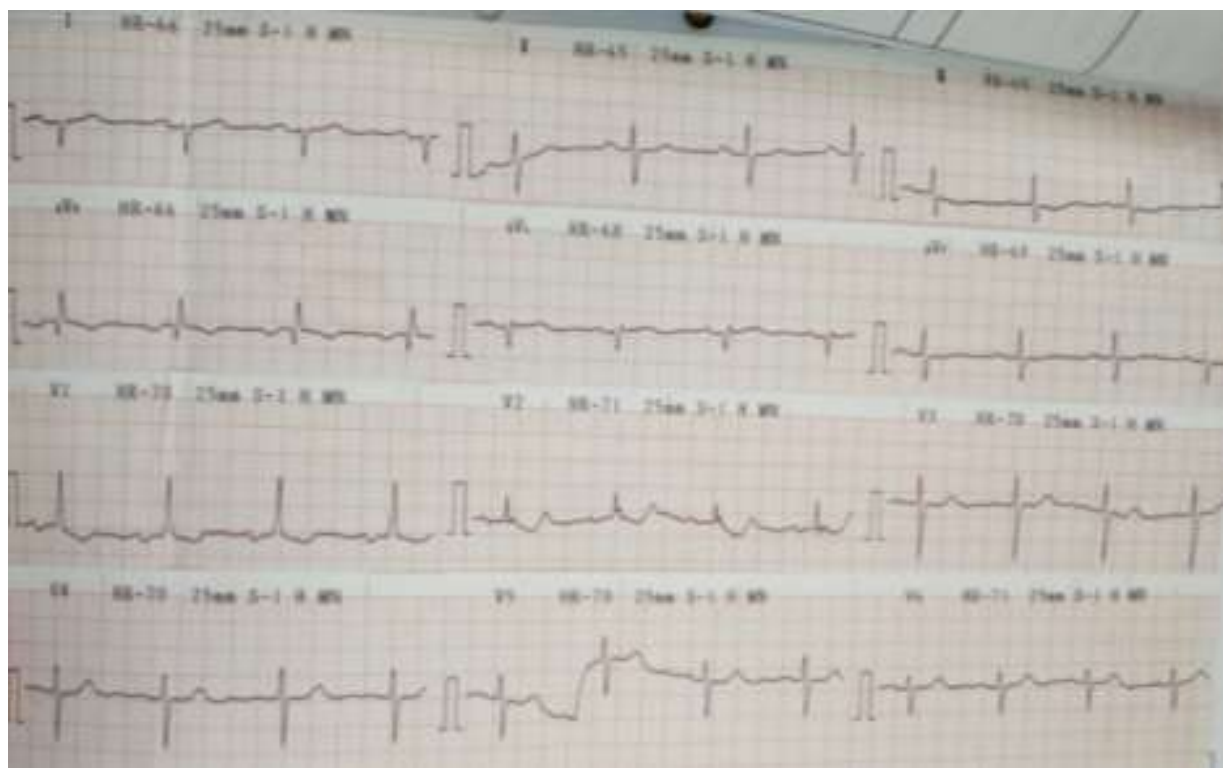

Figure 1. Electrocardiogram showed sinus rhythm 72 bpm, RAD, left atrial dilation and RV strain 


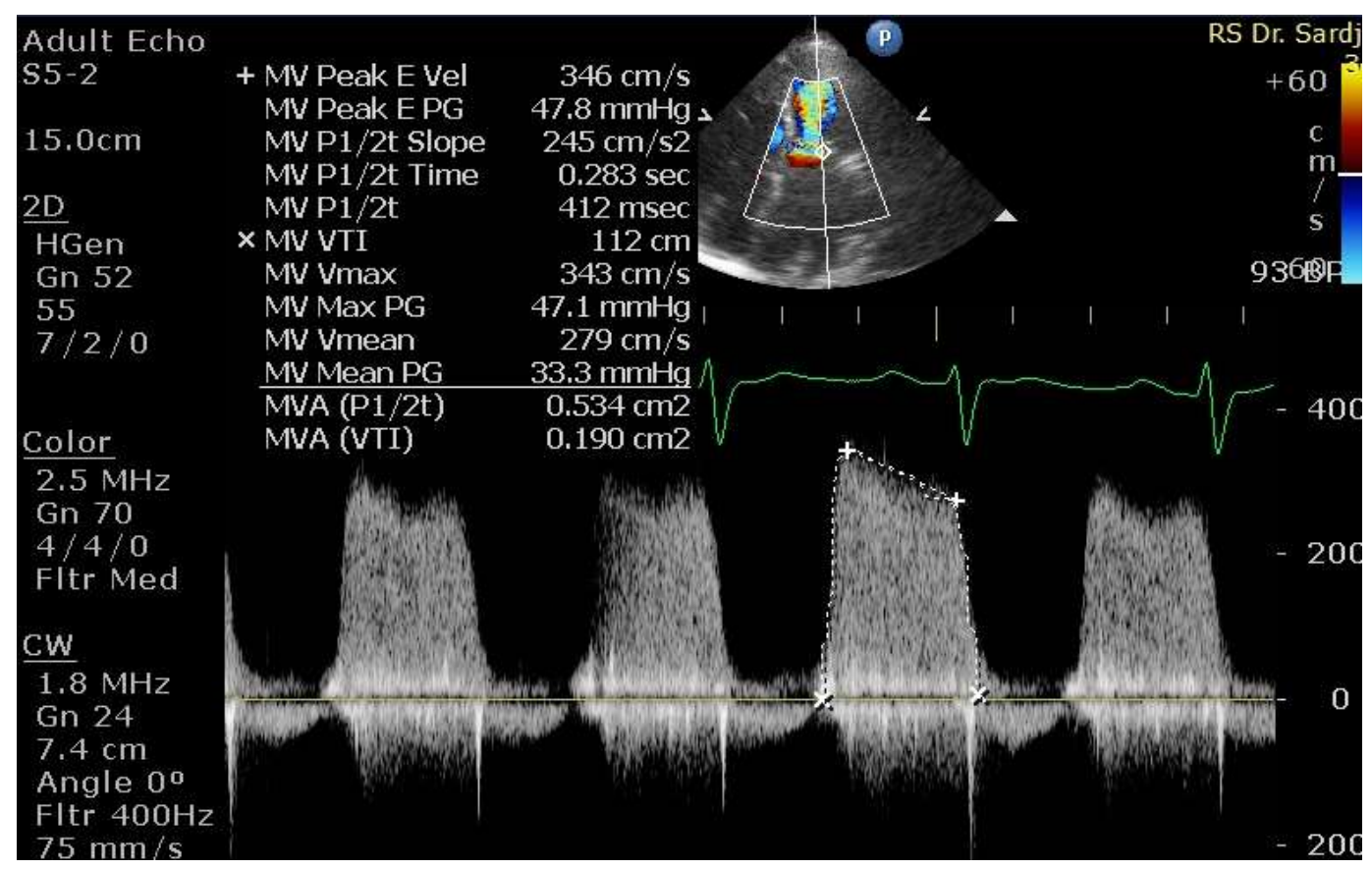

Figure 2. Transthoracic Echocardiography showed Severe Mitral Stenosis with MVA $0.53 \mathrm{~cm}^{2}$ and Mitral Valve Gradient (MVG) $33 \mathrm{mmHg}$.

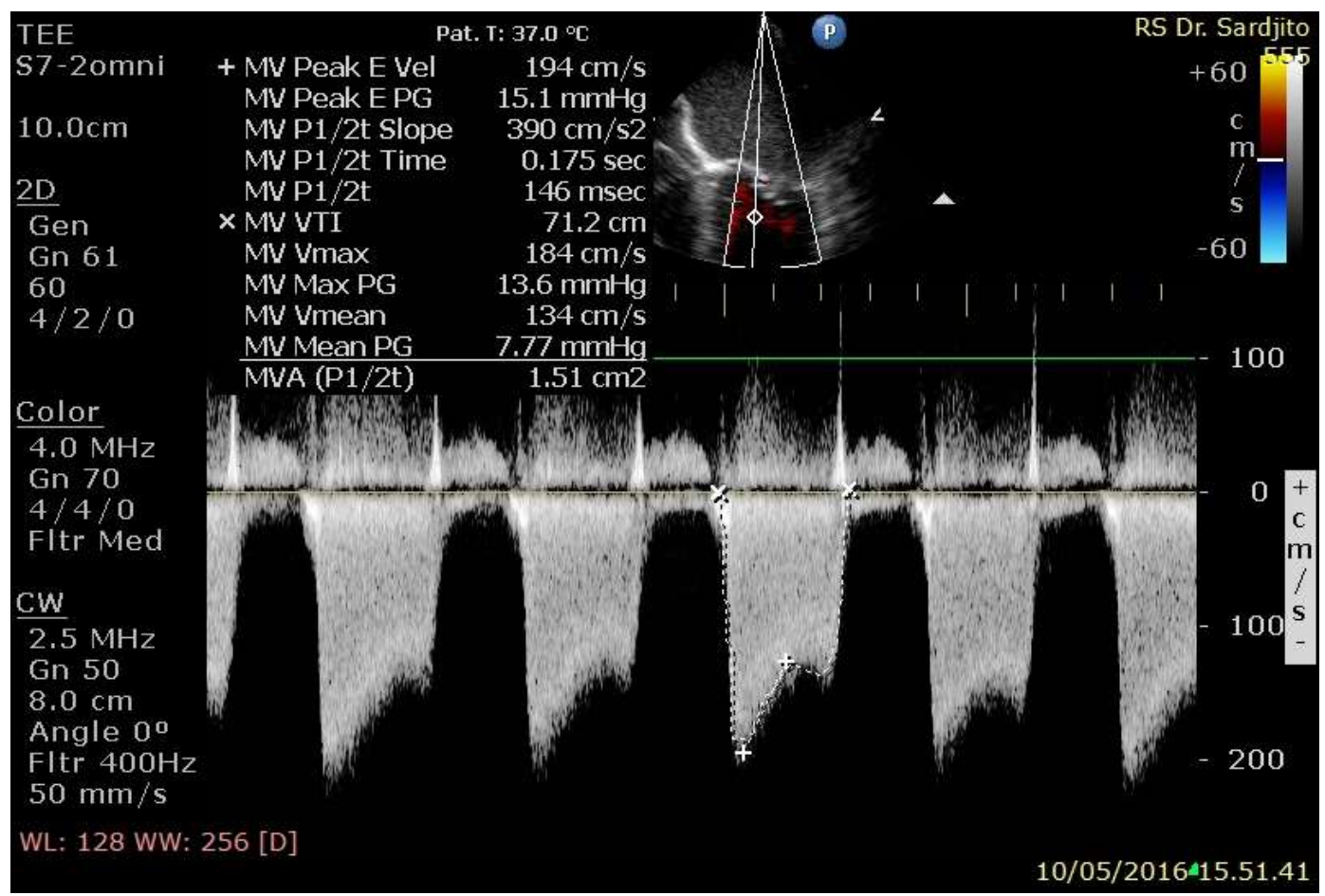

Figure 3. Transoesophageal Echocardiography Post procedure showed MVA $1.51 \mathrm{~cm}^{2}$ and MVG decreased $7 \mathrm{mmHg}$ 
The patient was diagnosed with congestive heart failure functional class II-III et causa diagnosis anatomy of MS severe, diagnosis etiology of rheumatic heart disease in patient G2P1A1 21 weeks gestation age.

The BMV procedure was performed at Dr. Sardjito Hospital. During and after the procedure there was no complication. The fetus was considered in stable condition. Echocardiography post procedure was MVG decreased $7 \mathrm{mmHg}$ and MVA $1.51 \mathrm{~cm}^{2}$. Patient then discharged from the hospital with therapy furosemide $40 \mathrm{mg}$ q.i.d., digoxin 1 tablet q.i.d., potassium supplemetation 1 tablet q.i.d. and warfarin $2 \mathrm{mg}$ q.i.d.

\section{DISCUSSION}

During normal pregnancy, the women's cardiovascular system will adapt to various hemodynamic changes such as increased heart rate, blood volume and vasodilation. ${ }^{5}$ These hemodynamic changes in the women's body occured from the time of conception to birth to meet the metabolic needs of the fetus. ${ }^{6}$ Hemodynamic changes during pregnancy started with the decreasing of systemic vascular resistance. Decreased vascular resistance is mediated by prostaglandin and increased production of nitric oxide. Nitric oxide is a vasodilator produced by the placental endothelium. This decrease in vascular resistance is accompanied by compensatory reaction by the kidneys to increased plasma volume and cardiac output. ${ }^{5}$

During normal pregnancy there is an increase of $20 \%-30 \%$ mass of erythrocytes and $30-50 \%$ of plasma volume. These changes lead to increase of blood volume with relative anemia. The pulse rate increases and there is a decrease in pulmonary and systemic vascular resistance, as well as a decrease in blood pressure. These hemodynamic changes result in increased cardiac output in early pregnancy until the $32^{\text {nd }}$ week of pregnancy. $^{7}$

The increasing of cardiac output during pregnancy will be redistributed selectively. Blood flow to the uterus will increase up to 10 times compared with non-pregnant conditions. Likewise there will be increased perfusion to the kidney, breast and skin. However, there is no autoregulation of increased cardiac output so perfusion to the uterus decreases if there is a decrease in blood flow from the mother as in the supine position. ${ }^{6}$

Pregnancy is also associated with hypercoagulatory status with decreased tissue plasminogen activator (TPA) and increased fastacting TPA inhibitors and factors $\mathrm{V}$, VII, VII, IX, X XII and von Willebrand. Protein $S$ increased and increased resistance to activated protein $\mathrm{C}$. In pregnant women with mitral stenosis, hemodynamic changes during pregnancy such as increased cardiac output and decreased vascular resistance will result in a greater pressure gradient between the left atrium and left ventricle and increased blood flow through the mitral valve. This condition can cause dilatation of the left atrium and pulmonary venous hypertension leading to pulmonary arterial hypertension and increased right ventricular overload so that the patient will suffer clinical decompensated heart failure. This condition especially manifest in the third trimester where plasma volume and heart rate are at their maximum. ${ }^{8}$ 
$\begin{array}{rr}\text { Ideally women with } & \text { MS } \\ \text { should do counseling and }\end{array}$ multidisciplinary education before deciding to get pregnant. There are several approaches to estimating the risk of cardiovascular complications in pregnant women. One of them is CARPREG score:

- Previous history of cardiac disease (heart failure, transient ischaemic attack, stroke, arrhythmia)

- Decreased of capacity function (NYHA>II) or cyanosis before pregnancy

- Left ventricular systolic function decreased (ejection fraction $<40 \%$ )

- Left heart obstruction (mitral valve area $<2 \mathrm{~cm}^{2}$, aortic valve area $<1.5 \mathrm{~cm}^{2}$ )

The presence of one predictor has possible complication in the mother up to $27 \%$ and the presence of more than one predictor up to $75 \%$. The patient has two predictorswhich are left heart obstruction, and the decrease of capacity function with increase with the age of pregnancy. Maternal complications are a worsening of symptoms of heart failure such as progresssion manifestation of heart failure and pulmonary edema. The Task Force recommends that maternal risk assessment is carried out according to the modified World Health Organization (WHO) risk classification. The patient was WHO class IV because of severe mitral stenosis and should be advised against pregnancy but she was decided to be pregnant. In this situation monthly or bimonthly review is needed. Maternal mortality rates vary from zero to three percent. Complications in the fetus or infant such as premature birth, small birth and respiratory distress. Preterm birth rates in mothers with MS were $20-30 \%$ and intrauterine growth disorders up to $5-20 \%{ }^{9}$ Fetal and neonatal mortality rates in mothers with mitral stenosis reach $4 \%{ }^{8}$

All patients with moderatesevere MS although asymptomatic should be counselledagainst pregnancy and intervention should be performed before pregnancy. Treatment options for mitral stenosis in pregnant women are medicamentous and intervention strategy such as correction with surgery or percutaneous intervention. Medical therapy includes limiting the activity, use of diuresis and beta blocker to reduce cardiac decompensation symptoms. Patients with atrial fibrillation, left atrial thrombus and embolism history are recommended for anticoagulant therapy. ${ }^{9}$

Intervention can be either percutaneous or surgical. Ideally performed after 20 weeks of gestation with some consideration of pregnant women with NYHA III/IV with and or an estimated pulmonary artery pressure greater than 50 $\mathrm{mmHg}$ despite optimal medical therapy. In percutaneous procedure should consider the minimum radiation dose..$^{9,10}$

The mortality rate of heart surgery in pregnant women is relatively high at 6 percent. This condition is due to surgical procedures performed in emergency situations and almost equal to the mortality rate of emergency cardiac surgery in general. However, maternal heart surgery with Cardiopulmonary Bypass (CBP) also gives a high fetal mortality rate up to $33 \%$. Increased gestational age and increased hypothermia are factors known to increase fetal morbidity 
during CPB. ${ }^{11}$ Thus surgical action is indicative in patients with symptoms not improving with aggressive medicament and percutaneous contraindications. $^{12}$ Contraindication of BMV are in patients with severe mitral regurgitation or if there is a left atrial thrombus. ${ }^{13}$

The maternal mortality rate for percutaneous valvulopathic procedure as low as $0.2 \%$ with a fetal mortality rate about $2 \%$ including elective termination. Percutaneous intervention success rate of $98 \%{ }^{12}$ Percutaneous valvuloplasty procedure may increase the NYHA class to functional class I or II. ${ }^{1}$ However, one of disadvantage of percutaneous procedure is exposure to radiation. If the patient is diagnosed with MS early in pregnancy, the procedure should wait until the 12-14 weeks of gestation to prevent exposure to radiation during the process of organogenesis. If there are indications of action at age 20 weeks, as much as possible until the age of 26 to 30 weeks to prevent the possibility of premature birth. ${ }^{12}$ According to the ESC Guideline in 2011 if percutaneous intervention is absolutely necessary, the best time for intervention is after the fourth month in the second trimester, when the organogenesis is complete, the fetal thyroid is still inactive and the uterine volume is small enough that the chest to the uterus is relatively distant. $^{9}$

Exposure to radiation to the fetus during pregnancy is depending on radiation dose and age at exposure. Radiation exposure can lead to inhibited growth of intrauterine, microchepalus, leukemia and various other malignancies. There is no reference value of radiation exposure in which an increased risk of congenital malformation occurs. The general principle in using radiation in pregnant women is to use minimal radiation or ALARA (as low as reasonably achievable). Up to now less than 50 mGy radiation exposure has not been shown to cause congenital malformations, intellectual decline, growth disorders or abortion. However, radiation exposure of more than $50 \mathrm{mGy}$ in fetuses over 14 days is thought to be associated with congenital malformations, impaired fetal and intellectual growth ${ }^{9}$. Documented doses of radiation causing intellectual disability are 610 mGy. ${ }^{14}$

The radiation exposure in various imaging procedures is not high. In radiation exposure to the fetus up to $1 \mathrm{mGy}$, the risk of cancer in children is very low. Termination of pregnancy simply because it has exposure to diagnostic radiation is not recommended. ${ }^{14}$ During the procedure of BMV, the patient was exposed to radiation with a dose of 408 mGy, above the estimated treshold dose. However, only a small amount of the radiation delivered on the thorax reaches the fetus. ${ }^{8}$ Although the procedure is effective, long term effects of foetal exposure to radiation during the use of fluoroscopy is a matter of concern and needs to be studied further. Studies show that infants of mothers who underwent BMV in the second and third trimester of pregnancy have normal long-term growth and development. However, because of the small sample size, the teratogenic effect of the ionising radiation cannot be totally excluded. Childhood malignancy is extremely rare and a study of this size cannot address this issue. Given the rarity of childhood malignancy, the benefits of the BMV probably 
outweight the possible increased risk of childhood malignancy. ${ }^{15}$ Beyond doubt it is now clear that radiation exposure after 20 weeks of gestation is unlikely to produce any form of major abnormalities. Most of the centres take only short time.

The dangers of radiation rays can be minimized by delaying the action during the process of organogenesis, using a curtain in the abdominal and pelvic areas, avoidance of left ventricular angiography, using echo cardiography as a guide during the action, using Inoue balloon technique and performed by experienced experts to reduce radiation exposure time. ${ }^{16}$ Use of the abdominal cavity is recommended, although it only reduces the dose of exposure to the fetus by $2 \%$, because the abdominal curtain can not prevent the spread of intraabdominal radiation. ${ }^{10}$ In the patient is subjected to a screen on the abdominal area to the pelvis, both front and rear.

Percutaneous BMV still have other risk during procedures other than radiation hazards, mitral regurgitant complications and cardiac tamponade which is hemodynamic changes. The haemodynamic risk is due to hypotension of the inferior compression of the glass vein when the mother is in a supine position during the procedure and the old balloon inflation. This causes fetal distress. ${ }^{17}$ Because of the risk of complications, percutaneous mitral commissurotomy should not be performed in asymptomatic mitral stenosis patients. $^{9}$

Study by Lee et al. (1993) and Sivadasanpillai et al. (2005) showed that children born to mothers who underwent BMV during pregnancy had normal development and growth. This patient was done BMV procedure because it proved relatively safe with low mortality and morbidity rates for both mother and fetus. $^{15,18}$ Gulraze et al. (2014) studied the seventeen years outcome of 23 cases of mitral balloon valvuloplasty during pregnancy. The children born of subsequent pregnancies exhibited normal pysical ad mental development. $^{1}$

\section{CONCLUSION}

A 33 years old woman came to Dr. Sardjito Hospital with shortness of breath during daily activities. Complaints are accompanied by swelling on both legs. The patient has been diagnosed with severe mitral stenosis. Patients are known to be pregnant with the third child, 21 weeks pregnant with history of first child miscarriage. The results of echocardiography showed MS severe Wilkin Score 8 with Mitral Valve area (MVA) $0.53 \mathrm{~m} 2$ and mitral Valve Gradient (MVG) 33 $\mathrm{mmHg}$, medium-severe regurgitation tricuspid (TR) with moderate pulmonary hypertension. The patient had done BMV with Echocardiography post procedure was MVG decreased $7 \mathrm{mmHg}$ and MVA increased $1.51 \mathrm{~cm} 2$.

Percutaneous procedure BMV in pregnant patients has been a concern to both medical worker and patients related to radiation exposure. However, BMV is more recommended than surgical procedures in pregnant women with severe MS with decompensated manifestation that are not resolved with medical therapy.

The maternal and fetal mortality rate for percutaneous valvulopathic procedure is low with 
high success rate. The dangers of radiation beam can be minimized by delaying the action during the process of organogenesis, using a curtain in the abdominal and pelvic areas, avoidance of left ventricular angiography, using echocardiography as a guide during the procedure, using Inoue balloon technique and performed by experienced experts to reduce radiation exposure time.

\section{REFERENCES}

1. Gulrate A., Kurdi W., Niaz F., Fawzy M. 2014. Mitral balloon valvuloplasty during pregnancy: The long term up to 17 years obstetric outcome and childhood development. Pak J Med Sci, 30:86-90.

2. Nanna M., Stergiopoulos K. 2014. Pregnancy complicated by valvular heart disease: An update. J Am Heart Assoc, 3:1-18.

3. French K.A., Poppas A. 2018. Rheumatic heart disease in pregnancy global challenges and clear opportunities. Circulation, 137:817-819.

4. Priya H.L., Bhandiwad A., Desai N., Kondareddy T., 2017. Maternal outcomes of rheumatic heart disease in pregnancy. Int J Reprod Contracept Obstet Gynecol, 6:802-806.

5. Ward C, James AH. Valvular Heart Disease and Pregnancy. 2009.

6. Wilansky S., Reuss C., Willerson J. 2007. Pregnancy and the heart. in: editors. Willerson J, Cohn J, Wellens $\mathrm{H}$, Holmes D. Cardiovascular Medicine. Third Edition. London; Springer, p:24532483.
7. Connolly, H.M. 2005. Pregnancy in women with congenital heart disease. Curr Cardiol Rep, 7: 305-309.

8. Karamermer Y., RoosHesselink J. 2007. Mitral stenosis before, during and after pregnancy. Int Cardio Res J, e80707:1-5.

9. Regitz-Zagrosek V., Blomstrom Lundqvist C., Borghi C., Cifkova R., Ferreira R., Foidart J.M., et al. 2011. ESC Guidelines on the management of cardiovascular diseases during pregnancy The Task Force on the Management of Cardiovascular Diseases during Pregnancy of the European Society of Cardiology, 32:3147-3197.

10. Pieper P.G., Hoendermis E.S., Drijver Y.N. 2012. Cardiac surgery and percutaneous intervention in pregnant women with heart disease. Neth Heart J, 20:125-128.

11. Patel A., Asopa S., Tang A.T., Ohri S.K. 2008. Cardiac surgery during pregnancy. Tex Heart Inst J, 35:307-312.

12. Norrad R.S., Salehian O. 2011. Management of severe mitral stenosis during pregnancy. Circulation, 124:2756-2760.

13. Mendelson M.A. 2004. Pregnancy in patients with obstructive lesions: Aortic stenosis, coarctation of the aorta and mitral stenosis. Progress in Pediatric cardiology, 19:61-70.

14. Copel J., El-Sayed Y., Heine R.P., Wharton K.R. 2017. Committee Opinion No. 723: Guidelines for diagnostic imaging during pregnancy and lactation. Obstet Gynecol, 130:e210-e216. 
15. Lee C.H., Chow W.H., Kwok O.H. 2001. Percutaneous balloon mitral valvuloplasty during pregnancy: long-term follow-up of infant. Hong Kong Med J, 7:85-88.

16. De Souza J.A., Martinez E.E., Ambrose J.A., Alves C.M., Born D., Buffolo E., et al. 2001. Percutaneous balloon mitral valvuloplasty in comparison with open mitral valve commissurotomy for mitral stenosis during pregnancy. $\mathrm{J}$ Am Coll Cardiol, 37:900-903.
17. Routray S.N., Mishra T.K., Swain S., Patnaik U.K., Behera M. 2004. Balloon mitral valvuloplasty during pregnancy. Int $J$ Gynaecol Obstet, 85:18-23.

18. Sivadasanpillai H., Srinivasan A., Sivasubramoniam S., Mahadevan K.K., Kumar A., Titus T., et al. 2005. Long-term outcome of patients undergoing balloon mitral valvotomy in pregnancy. Am J Cardiol, 95:1504-1506. 